\title{
PERFORMANCE EVALUATION AND INDICES OF CYBER CAFÉ BUSINESS: A FACTOR ANALYTIC APPROACH
}

\author{
Oluwadare Samuel Adebayo \\ Department of Computer Science, \\ Federal University of Technology, \\ P.M.B. 704, Akure \\ oluwadaresam@yahoo.com
}

\begin{abstract}
The advent of the World Wide Web has opened up a new vista of opportunities for investment in the Information Communication Technology (ICT) industry. In recent years, the cyber cafe business has attracted considerable investment, providing job opportunities for many people. On the other hand, it has also been observed that some hitherto vibrant cyber cafes are also closing down due to the fact that they could not break even. This study, is therefore, aimed at identifying the factors/ indices that could enhance the performance of cyber cafes. A total of 250 users of cyber cafes in Akure, Ondo State, Nigeria were randomly selected and a structured questionnaire was administered on them. Data collected was analysed using factor analysis by principal component. The result revealed that four factors, namely quality of hardware, speed of processing, cost, and reliability of service are the major factors that influence users' patronage. It is therefore recommended that investors and would-be-investors in the cyber cafe business should pay attention to these facors in order to enhance the success of their investment.
\end{abstract}

Keywords: Performance evaluation, Indices, Cyber cafe, Factor analysis.

\section{INTRODUCTION}

The increased awareness and usage of Internet services by Nigerians has led to investors committing resources to the establishment of cyber cafe businesses. Most urban centres in Nigeria have witnessed an unprecedented 
upsurge in the establishment of cyber cafes. Oluwadare (2006) noted that in the last decade, there has been unprecedented upsurge in the flow/movement of people, information, goods, and services across the globe. This trend has placed a heavy demand on ICT facilities which are at its infancy in Nigeria. The provision of broadband Internet services to all Nigerians is still a goal to be achieved given the poor state of basic infrastructure, poverty, illiteracy, inequalities, and the divide along rural/urban, and gender lines among others. With the Internet penetration rate of 1.1\% (Internet World Stats, 2006), Nigeria has one of the lowest Internet penetration rates in the world.

\section{Motivation for the Study}

Knowledge is fast becoming the universal currency of the $21^{\text {st }}$ century, and since knowledge is derived to a large extent from information, ICT will continue to play a pivotal role in the transformation of human societies. Given the low Internet penetration rate in Nigeria, the need to encourage investment in ICT services cannot be over-emphasised. The current structure of cyber cafe businesses in Nigeria need to be fine-tuned in order to make them provide better and increased access to Internet services. This has necessitated the need to identify the factors or indices that would enhance their overall performance and profitability.

\section{RESEARCH METHODOLOGY}

This section describes the methodology used for conducting the study. This includes the study area, sources of data, sampling technique, and the method of data analysis.

\section{Background of Study Area}

The study area is Akure, the capital city of Ondo State, Nigeria. Ondo State is one of the 36 states of Nigeria. The population of Akure is made up of civil servants, professionals, artisans, traders, farmers, and students. Being the State capital, Akure is the hub of economic, social, political, and ICT activities in Ondo State. 


\section{Sources of Data}

The data used for the study was derived from primary source by means of a structured questionnaire.

\section{Sampling Technique}

The research population consists of 124 registered cyber cafe in Akure out of which 25 cyber cafes were randomly chosen. This represents $20.16 \%$ of the research population. Ten customers of the cyber cafes were also randomly sampled and a structured questionnaire was administered on them. In all, a total of 250 respondents were covered by this study.

\section{Questionnaire Design}

The questionnaire centres around the demographic characteristics of the respondents and 25 variables that could influence the performance of cyber cafes. Respondents were asked to give their opinion on the importance of each variable that affect the performance of cyber cafes on a five point Likert scale: Strongly Agree $=5$, Agree $=4$, Undecided $=3$, Disagree $=2$, Strongly Disagree $=1$.

\section{Demographic Characteristics of Respondents}

The analysis of the demographic characteristics of the respondents is presented in Table 1 .

Table 1 revealed that $60.0 \%$ of the respondents are male while $40.0 \%$ are female. Analysis of age distribution revealed that the modal age of the respondents is between 21 and 30 years. Only $16.0 \%$ are above 40 years. This clearly showed that the majority of those that patronise cyber cafe are 
Table 1: Demographic Characteristics of Respondents

\begin{tabular}{|c|c|c|}
\hline Variable & Frequency & Percentage $(\%)$ \\
\hline \multicolumn{3}{|l|}{ a. Gender } \\
\hline Male & 150 & 60.0 \\
\hline Female & 100 & 40.0 \\
\hline \multicolumn{3}{|l|}{ Age (years) } \\
\hline Less than 20 & 10 & 4.0 \\
\hline $21-30$ & 150 & 60.0 \\
\hline $31-40$ & 50 & 20.0 \\
\hline Above 40 & 40 & 16.0 \\
\hline \multicolumn{3}{|l|}{ b. Marital Status } \\
\hline Single & 155 & 62.0 \\
\hline Married & 85 & 34.0 \\
\hline Divorced/Separated & 10 & 4.0 \\
\hline \multicolumn{3}{|l|}{ c. Years of Internet Usage } \\
\hline Less than 1 & 5 & 2.0 \\
\hline $1-2$ & 19 & 7.6 \\
\hline $3-5$ & 120 & 78.0 \\
\hline Above 5 & 106 & 42.4 \\
\hline \multicolumn{3}{|c|}{ d. Highest Educational Level } \\
\hline No formal education & 5 & 2.0 \\
\hline Primary school & 10 & 4.0 \\
\hline Secondary school & 85 & 34.0 \\
\hline Tertiary school & 150 & 60.0 \\
\hline \multicolumn{3}{|c|}{ e. Monthly Income (Naira) } \\
\hline Less than $\mathrm{N} 10,000$ & 10 & 4.0 \\
\hline $\mathrm{N} 10,001-20,000$ & 18 & 7.2 \\
\hline $\mathrm{N} 20,001-30,000$ & 85 & 34.0 \\
\hline $\mathrm{N} 30,001-40,000$ & 112 & 44.8 \\
\hline $\mathrm{N} 40,001-50,000$ & 15 & 6.0 \\
\hline Above N50,000 & 10 & 4.0 \\
\hline \multicolumn{3}{|c|}{ f. Training on Internet Use } \\
\hline Yes & 164 & 65.6 \\
\hline No & 86 & 34.4 \\
\hline \multicolumn{3}{|c|}{ g. Frequency of Visit to Cyber Cafes } \\
\hline Daily & 89 & 35.6 \\
\hline Weekly & 143 & 57.2 \\
\hline Monthly & 13 & 5.2 \\
\hline Greater than a month & 5 & 2.0 \\
\hline
\end{tabular}

$\mathrm{N}=250$

Source: Field (2006)

the youth. In terms of marital status, the majority (62.0\%) are single, $34.0 \%$ are married and $4.0 \%$ are divorced or separated. This further confirmed that most of those that patronise cyber cafe are the youth. Also, in terms of years of usage of the Internet, $2.0 \%$ have been using the Internet for less than one 
year, $7.6 \%$ for between 1 and 2 years, $48.0 \%$ for between 3 and 5 years, while $42.4 \%$ for above 5 years. A closer look at Table 1 showed that about $90.4 \%$ of the respondents have been using the Internet for over 3 years.

With respect to the educational background of the respondents, the Table 1 also revealed that $2.0 \%$ had no formal education, $4.0 \%$ attended primary school, $34.0 \%$ attended secondary school, and $60.0 \%$ attended tertiary school (university, polytechnic, and college of education). Furthermore, analysis of monthly income of respondents revealed that $4.0 \%$ earn less than N10,000 monthly income, $7.2 \%$ earn between $\mathrm{N} 10,000$ and $\mathrm{N} 20,000,34.0 \%$ earn between $\mathrm{N} 21,000$ and $\mathrm{N} 30,000,44.8 \%$ earn between $\mathrm{N} 31,000$ and $\mathrm{N} 40,000$, $6.0 \%$ earn between $\mathrm{N} 41,000$ and $\mathrm{N} 50,000$, while $4.0 \%$ earn above $\mathrm{N} 50,000$ monthly. Concerning training in the use of Internet, $65.6 \%$ indicated that they had training on the use of the Internet while $34.4 \%$ indicated that they had no training on the use of Internet. With respect to the frequency of visit to cyber cafes, $35.6 \%$ visit cyber cafes daily, $57.2 \%$ visit weekly, $5.2 \%$ visit monthly, and $2.0 \%$ indicated that the frequency of their visit is above one month.

\section{Variables Used in the Analysis}

The following variables, which affect the performance indices of cyber café were used in the analysis.
(a) Availability of service (AVS)
(b) Service interruption /Failure rate (SIF)
(c) Location of cyber cafe (Accessibility) (LCC)
(d) Operating hours $(\mathrm{OPH})$
(e) Cost of service per minute (CSM)
(f) Cost of service per hour (CSH)
(g) Cost of service per day (CSD)
(h) Efficiency of service (EFS)
(i) Satisfaction with service (SWS)
(j) Assessment of download time (ADT)
(k) Assessment of response time (ART)
(l) Average waiting time (AWT)
(m) Power reliability (electricity) (PRE)
(n) Assessment of upload time (AUT)
(o) Competence of staff (COS)
(p) Quality of hardware (QTH)
(q) Quality of auxiliary service, printing, and scanning (QAS)
(r) Back up facilities, CD ROM, Flash drive, Diskette, etc. (BUF)
(s) Quality of furniture (QLF) 
(t) Seating arrangement (SAR)

(u) Environmental quality, e.g. air conditioner, lighting, etc. (EQL)

(v) Security (SEC)

(w) Waiting time before you can secure a workstation to work with (WTW)

(x) Number of computers (NCO)

(y) Virus problem (VIP)

\section{Method of Data Analysis}

Factor analysis by principal components was adopted in the data analysis for the purpose of partitioning of the variables into factors that influence performance of cyber cafes. The purpose of factor analysis is to summarise the interrelationship and establish levels of variances in decision variables as they influence the given phenomenon. A factor is simply a linear combination of variables. The linear combination is not chosen arbitrarily, but in order to capture the relationship among the variables, factor analysis uses the correlation or covariance among a set of observed variables to describe them in terms of a smaller set of unobservable variables. The unobservable variables called factors, describe the underlining relationship among the original variables. Factor analysis requires a set of data points in matrix form with the row and column identifying the matrix (Cattell, 1949; Tucker \& MacCallum, 1993; Olorunleke, 2006). The Factor Analysis Model is given as:

$$
\underset{(\mathrm{p} \times 1)}{\left(\mathrm{X}_{\mathrm{i}} \mid \hat{\mathrm{y}}, \lambda, \mathrm{f}_{\mathrm{i}}, \mathrm{m}\right)}=\underset{(\mathrm{p} \times 1)}{\hat{\mathrm{y}}}+\underset{(\mathrm{p} \times \mathrm{m})(\mathrm{m} \times 1)}{\lambda \mathrm{f}_{\mathrm{i}}}+\underset{(\mathrm{p} \times 1)}{\varepsilon_{\mathrm{i}}}
$$

where $\hat{y}$ is the overall population mean vector,

$\lambda$ is the factor-loading matrix,

$\mathrm{f}_{\mathrm{i}}$ is the factor score,

$\mathrm{m}$ is the number of factors, $\mathrm{p}$ is the observed variables, $\varepsilon_{i}$ is the error variance, and $i$ is the number of observation.

In factor analysis, attention is paid to the central limit theorem. Here the errors $\left(\varepsilon_{i}\right)$ are assumed to be normally distributed with mean 0 and constant variance. Factor scores and errors are independent. Factor analysis also assumes that all variables are dependent and there are no independent variables. 


\section{RESULTS AND DISCUSSION}

\section{Test of Sampling Adequacy}

The Bartlett's test of sphericity was used in the test for the appropriateness of the sample from the population and the suitability of factor analysis. It tests for the adequacy of the sample as a true representation of the population under study (Alese \& Owayemi, 2004).

Table 2: KMO and Bartletts Test of Sphericity

\begin{tabular}{llc}
\hline Kaiser- mayer -Olkin measure of sampling Adequacy & 0.888 \\
Martlett'sTest of sphericity & Approx. Chi square & 2077.117 \\
& Df & 300 \\
sig & 000 \\
\hline
\end{tabular}

The Bartlett's test Table 2 shows a chi-square of 2077.117 and a significant level of 0.000 , which is an indication of the adequacy of the sample. The Kaiser Mayer Olkin (KMO) test is another measure of sample adequacy. It is an index for comparing magnitudes of the observed correlation coefficients between all pairs of variables. It is small when compared to the sum of the squared correlation coefficient. A KMO value of 1 represents a perfectly adequate sample. A KMO of 0 represents a perfectly inadequate sample. The $\mathrm{KMO}$ value in Table 2 is 0.888 , which shows that the sample is reasonably adequate.

\section{Communalities}

The communalities are shown in Table 3. It shows the proportion of the variances explained by the common factors. The communalities are in the range 0 and 1 , with 0 indicating that the common factors (extracted) explain none of the variances in the variable and 1 indicating that the common factors explain all of the variance in the variable. It could also be expressed as a percentage. For instance, the availability of service (AVS) is 0.588 which indicates that $58.8 \%$ of the variances in availability of service is accounted for by the common factors while the remaining $41.2 \%$ is accounted for by unique (unexplained) factors. The initial communalities are always 1.00 before the extraction of factors because at that initial stage every variable is regarded as a factor with a mean of 0 and standard deviation of 1 . 
Table 3: Communalities

\begin{tabular}{lcc}
\hline & Initial & Extraction \\
\hline Availability of service (AVS) & 1.000 & .588 \\
Service interruption /failure (SIF) & 1.000 & .584 \\
Location of cyber cafe (accessibility) (LCC) & 1.000 & 706 \\
Operating hours (OPH) & 1.000 & .749 \\
Cost of service per minute (CSM) & 1.000 & .775 \\
Cost of service per hour (CSH) & 1.000 & .829 \\
Cost of service per day (CSD) & 1.000 & .788 \\
Efficiency of service (EFS) & 1.000 & .726 \\
Satisfaction with service (SWS) & 1.000 & .677 \\
Assessment of download time (ADT) & 1.000 & .810 \\
Assessment of response time (ART) & 1.000 & .771 \\
Average waiting time (AWT) & 1.000 & .670 \\
Power reliability (electricity) (PRE) & 1.000 & .524 \\
Assessment of upload time (AUT) & 1.000 & .754 \\
Competence of staff (COS) & 1.000 & .649 \\
Quality of hardware (QLH) & 1.000 & .779 \\
Quality of auxiliary services - printing, scanning, etc. (QAS) & 1.000 & .674 \\
Backup facilities - CDROM, flash drive, diskette etc. (BUF) & 1.000 & .679 \\
Quality of furniture (QLF) & 1.000 & .834 \\
Sitting arrangement (SAR) & 1.000 & .751 \\
Environmental quality, e.g. air conditioner, lighting. Etc. & 1.000 & .828 \\
(EQL) & & \\
Security (SEC) & 1.000 & .757 \\
Waiting time you can secure a workstation & 1.000 & .536 \\
(WTW) & & \\
Number of computers (NCO) & 1000 & .540 \\
Virus problem (VIP) & 1000 & .527 \\
\hline Extraction Method: Principal Component Analysis & & \\
\hline & & \\
\hline
\end{tabular}

Extraction Method: Principal Component Analysis

\section{Factor Extraction}

The 25 variables used in the study were subjected to factor extraction by principal component. The output of the analysis contained the initial component matrix which was subjected to rotation in order to fine tune the loadings on each factor. The initial Eigen values, the percentage variance explained, and the rotation sum of square loadings are presented in Table 4. 
Table 4: Total Variance Explained (Rotation Sums of Squared Loadings)

\begin{tabular}{|c|c|c|c|c|c|c|}
\hline \multirow[b]{2}{*}{ Component } & \multicolumn{3}{|c|}{ Initial Eigenvalues } & \multicolumn{3}{|c|}{ Rotation Sums of Squared Loadings } \\
\hline & Total & $\%$ of Variance & $\begin{array}{l}\text { Cumulative } \\
\%\end{array}$ & & $\%$ of Variance & Cumulative $\%$ \\
\hline 1 & 12.625 & 50.502 & 50.502 & 5.912 & 23.649 & 23.649 \\
\hline 2 & 2.099 & 8.397 & 58.899 & 4.792 & 19.168 & 42.818 \\
\hline 3 & 1.473 & 5.894 & 64.792 & 4.451 & 17.805 & 60.623 \\
\hline 4 & 1.308 & 5.233 & 70.025 & 2.351 & 9.403 & 70.025 \\
\hline 5 & .993 & 3.973 & 73.998 & & & \\
\hline 6 & .775 & & 77.100 & & & \\
\hline \multirow[t]{2}{*}{7} & .757 & 3.029 & 80.129 & & & \\
\hline & .716 & 2.862 & 82.991 & & & \\
\hline 9 & .627 & & 85.500 & & & \\
\hline 10 & .549 & 2.196 & 87.696 & & & \\
\hline 11 & .477 & 1.909 & 89.605 & & & \\
\hline 12 & .411 & 1.644 & 91.249 & & & \\
\hline 13 & .377 & 1.506 & 92.755 & & & \\
\hline 14 & .277 & 1.108 & 93.864 & & & \\
\hline 15 & .270 & 1.082 & 94.945 & & & \\
\hline 16 & .228 & .912 & 95.857 & & & \\
\hline 17 & .186 & .743 & 96.600 & & & \\
\hline 18 & .159 & .634 & 97.235 & & & \\
\hline 19 & .147 & .587 & 97.822 & & & \\
\hline 20 & .123 & .492 & 98.314 & & & \\
\hline \multirow[t]{2}{*}{21} & .110 & .440 & 98.754 & & & \\
\hline & $9.353 \mathrm{E}-02$ & .374 & 99.128 & & & \\
\hline 23 & 8.897E-02 & .356 & 99.484 & & & \\
\hline 24 & $8.225 \mathrm{E}-02$ & .329 & 99.813 & & & \\
\hline 25 & 4.680E-02 & .187 & 100.000 & & & \\
\hline
\end{tabular}

There are two forms of rotation viz: orthogonal and oblique rotation. Orthogonal rotation assumes that the factors are uncorrelated, whereas oblique rotation allows for some minor correlations among factors (Abdi, 2003). The rotation methods explored were varimax, promax, equamax, and direct oblimin. Varimax, which is an orthogonal rotation method, was adopted based on the fact that it produced more meaningful loadings and also because the rotation converged after seven iterations, which happened to be the least. The result of the varimax rotation was used for interpretation. The rotated component matrix is presented in Table 5. 
Table 5: Rotated Component Matrix Varimax

\begin{tabular}{lllll}
\hline & Factor 1 & Factor 2 & Factors 3 & Factor 4 \\
\hline EQL & 0.848 & & & \\
QLF & 0.839 & & & \\
SAR & 0.811 & & & \\
QTH & 0.733 & & & \\
WTW & 0.622 & & & \\
NCO & 0.591 & & & \\
BUF & 0.589 & & & \\
QAS & 0.575 & & & \\
AVS & 0.521 & 0.767 & & \\
ART & & 0.753 & & \\
ADT & & 0.707 & & \\
SWS & & 0.671 & & \\
AWT & & 0.626 & & \\
EFS & & 0.574 & & \\
SIF & & 0.606 & 0.811 & \\
AUT & & & 0.786 & \\
CSH & & & 0.758 & \\
LOC & & & 0.749 & \\
CSD & & & 0.710 & \\
CSM & & & & 0.731 \\
OPH & & & & 0.606 \\
COS & & & & 0.801 \\
AUT & & & & \\
PRE & & & & \\
SEC & & & & \\
VIP & & & \\
\hline
\end{tabular}

Rotation converged in 7 iterations.

The number of factors to be retained were specified on the basis of a social science rule which states that only the variable with a loading equal to or greater than 0.4 in absolute terms and percentage of variance greater than 1 should be considered meaningful and extracted for factor analysis. The result presented in Table 5 was obtained based on this rule. A total of four factors were extracted and the following four factor groupings were obtained.

Factor 1: Quality of facilities: Environment, hardware, furniture, and availability of service
(a) Environmental quality (e.g. air conditioner, lighting etc.).
(b) Quality of furniture
(c) Sitting arrangement
(d) Quality of hardware
(e) Waiting time before you can secure a workstation to work with
(f) Number of computers 
(g) Backup facilities (e.g. CDROM, flash drive, diskette, etc.)

(h) Quality of auxiliary services printing, etc.

(i) Availability of service

\section{Factor 2: Response time/Speed of processing}
(a) Download time
(b) Upload time
(c) Satisfaction with service
(d) Average waiting time
(e) Efficiency of service
(f) Service interruption / Failure rate
(g) Assessment of response time

\section{Factor 3: Cost of service}
(a) Cost of service per day
(b) Cost of service per hour
(c) Cost of service per minute
(d) Operating hours

\section{Factor 4: Other factors}
(a) Competence of staff
(b) Power reliability (electricity)
(c) Security
(d) Virus problem
(e) Location of cyber cafe

From the factor loadings and Table 4 , it could be observed that quality of facility factors (factor 1) contributes $23.649 \%$ to performance, while response time/speed of processing, cost of service, and other factors contribute $19.168 \%, 17.805 \%$, and $9.403 \%$, respectively. The four factors contribute a total of $70.025 \%$ while the remaining $29.975 \%$ is accounted for by extraneous factors, which are unique to the variables and other variables outside the control of the researcher.

\section{Performance Evaluation of Individual Cyber Cafes}

Factors can be estimated as a linear combination of the original variables. From the component score coefficient matrix shown in Table 6, we can form such linear relationships. This can be used to estimate the performance of individual cyber cafes based on the four factors extracted. This can be achieved by forming a linear equation of the weighted standard scores of the cyber cafes of the variable. 
Table 6: Component Score Coefficient Matric

\begin{tabular}{lcccc}
\hline & \multicolumn{4}{c}{ Component } \\
\cline { 2 - 5 } & 1 & 2 & 3 & 4 \\
\hline AVS & 0.70 & .100 & .003 & -.075 \\
SIF & .007 & .124 & .045 & -.041 \\
LCC & -.025 & .008 & .233 & -.090 \\
OPH & .030 & -.055 & .187 & .093 \\
CSM & -.046 & .058 & .197 & -.029 \\
CSH & .008 & -.060 & .230 & .071 \\
CSD & .005 & .002 & .200 & -.001 \\
EFS & -.002 & .128 & .055 & .002 \\
SWS & -.011 & .180 & -.081 & 0.99 \\
ADT & -.010 & .180 & .013 & -.021 \\
ART & -.014 & .196 & .006 & -.065 \\
AWT & -.028 & .156 & -.013 & .096 \\
PRE & -.020 & .022 & .018 & .284 \\
AUT & -.017 & .100 & -.034 & .266 \\
COS & .016 & -.037 & -.006 & .385 \\
QTH & .130 & -.011 & .037 & .040 \\
QAS & .087 & -.004 & .040 & .122 \\
BUF & .087 & .025 & .047 & .037 \\
QLF & .164 & .028 & -.043 & -.036 \\
SAR & .163 & .013 & -.049 & -.014 \\
EQL & .170 & -.014 & .008 & -.053 \\
SEC & .172 & -.086 & -.010 & .127 \\
WTW & .112 & .041 & -.047 & .027 \\
NCO & .117 & -.036 & .101 & -1.65 \\
VIP & .030 & .166 & -.004 & -.322 \\
\hline
\end{tabular}

Extraction Method: Principal Component Analysis.

Rotation Method: Promax with Kaiser Normalisation.

If the standard scores of the it-h cyber cafes in the 25 variables under consideration are $\mathrm{S}_{\mathrm{i}, 1}, \mathrm{~S}_{\mathrm{i}, 2}, \mathrm{~S}_{\mathrm{i}, 3}, \ldots, \mathrm{S}_{\mathrm{i}, 25}$, then the assessment of the performance of the cyber cafés considering the four factors, denoted by $\mathrm{C}_{\mathrm{j}}, \mathrm{j}=1,2,3,4$, are defined by:

$$
\begin{aligned}
& \mathrm{C}_{1}=-(0.070) \mathrm{S}_{1,1}+(0.007) \mathrm{S}_{1,2}-(0.025) \mathrm{S}_{1,3} \ldots+(0.030) \mathrm{S}_{1,2} \\
& \mathrm{C}_{2}=(0.100) \mathrm{S}_{2,1}+(0.124) \mathrm{S}_{2,2}+(0.008) \mathrm{S}_{2,3} \ldots+(0.166) \mathrm{S}_{2,2} \\
& \mathrm{C}_{3}=(0.003) \mathrm{S}_{3,1}+(0.045) \mathrm{S}_{3,2}+(0.233) \mathrm{S}_{3,3} \ldots-(0.004) \mathrm{S}_{3,25} \\
& \mathrm{C}_{4}=-(0.75) \mathrm{S}_{4,1}-(0.041) \mathrm{S}_{4,2}-(0.090) \mathrm{S}_{4,3} \ldots-(0.322) \mathrm{S}_{4,25}
\end{aligned}
$$


For each of the factors, a system of equations for the sample population of the following general form is obtained.

$$
\left[\begin{array}{cccc}
b_{1,1} & S_{1}+b_{1,2} & S_{2}+b_{1,3} S_{3}+\ldots+b_{1,25} & S_{25} \\
\vdots & \vdots & \vdots & \vdots \\
\vdots & \vdots & \vdots & \vdots \\
b_{m, 1} S_{1}+b_{m, 2} S_{2}+b_{m, 3} S_{3}+\ldots+b_{m, 25} S_{25}
\end{array}\right]=\left[\begin{array}{l}
C_{1} \\
\vdots \\
\vdots \\
C_{m}
\end{array}\right]
$$

In an attempt to evaluate the percentage contribution of each factor to performance of cyber cafes, the Eigenvalues and percentage variance of each factor after the extraction of factors are exhibited in Table 4. The social science rule earlier referred to stipulates that only factors with Eigen values of 1 and above are considered meaningful for interpretation.

\section{CONCLUSION}

This research focused on the performance evaluation and indices of cyber cafe businesses in Akure, Ondo State, Nigeria using a factor analytic approach. A random sample of 25 out of a total of 124 registered cyber cafes in Akure metropolis were selected for the study. Ten users of each of the selected cyber cafe were also randomly sampled and their opinion was sought with the aid of a structured questionnaire. The questionnaire comprised two sections namely the demographic characteristics of the respondents and a section in which their opinion was sought on some 25 variables that may influence patronage of cyber cafe. The opinion was rated on a five-point Likert scale.

The results of the factor analysis reduced the variables necessary for the optimum performance of cyber cafe businesses into four factors, namely quality factors, speed of processing, cost of service, and other factors. The four factors produced a cumulative loading of $70.02 \%$. It is recommended that efforts should be made at planning a feasibility study stage of investment decision to ensure that all these factors are taken into consideration before investing in a cyber cafe business. The government and all stakeholders should provide the basic infrastructure that would promote cyber cafe businesses in Nigeria. 


\section{REFERENCES}

Abdi, H. (2003). Factor rotations in factor analyses. In M. Lewis-Beck, A. Bryman, \& T. Futing (Eds.). Encyclopedia for research methods for the social sciences (pp. 792-795). Thousand Oaks (CA): Sage.

Adomi, E.E. (2004). The use cyber cafe in Nigeria. Universities Library Hitech, 22(4), 38-85.

Alese, B.K., \& Owoyemi, S.O. (2004). Factor analytic approach to Internet usage in South Western Nigeria. Journal of Information Technology Impact, 4(3), 171-188.

Cattell, R. (1949). The dimensions of culture patterns by factorisation of national characters. Journal of Abnormal and Social Psychology, 44, 443-469.

Internet World Stats. (2006). World Internet usage and population. Retrieved November 16, 2006 from http://www.internetworldstats.com/stats. htm.

Olorunleke, G. K. (2006). Managing customer for brand equity in carbonated soft drinks market in Nigeria: A case study of Pepsi. Unpublished doctoral dissertation, Dept. of Business Administration, University of Ilorin, Nigeria.

Oluwadare, S.A. (2006). Nigeria in the World Information Order: The challenges of the digital divide. Journal of the National Association of Science, Humanities, and Education Research (NASHER), 4(2), 117124.

Tucker, L., \& MacCallum R. (1993). Exploratory factor analysis - A Book Manuscript. Retrieved June 8, 2006, from: http://www.unc.edu/ rcm/ book/factornew.htm. 